\title{
Rando Fig S2
}

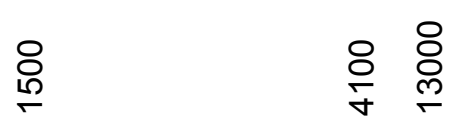

Nucleosomes

H3K4Me1

H3K4Me2

H3K4Me3

H3K18Ac

H4K12Ac

H3K9Ac

H3K14Ac

H4K5Ac

H2AK7Ac

H4K8AC

H4K16Ac

H2BK16AC

PanAc

Polll
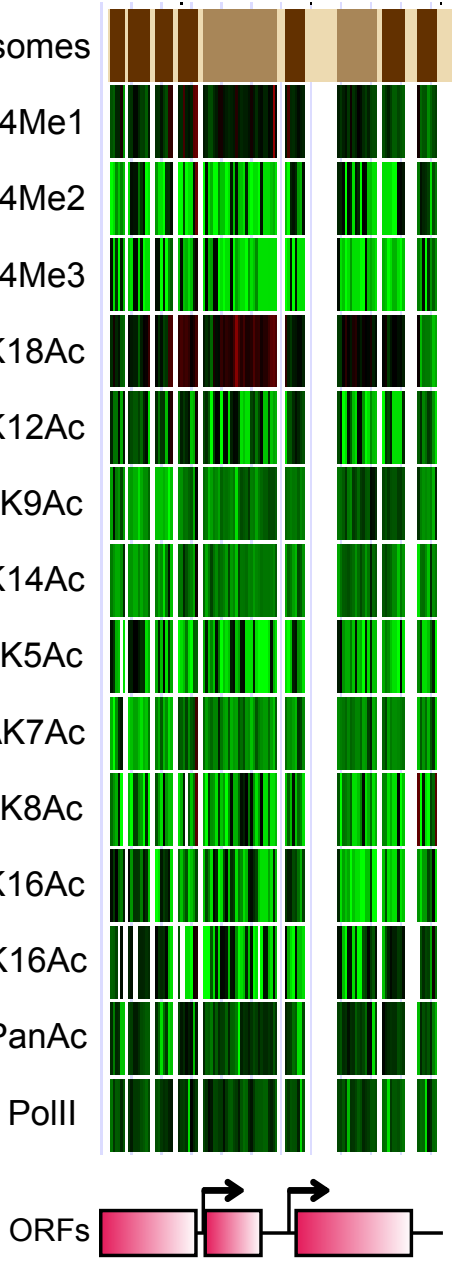

ARSs
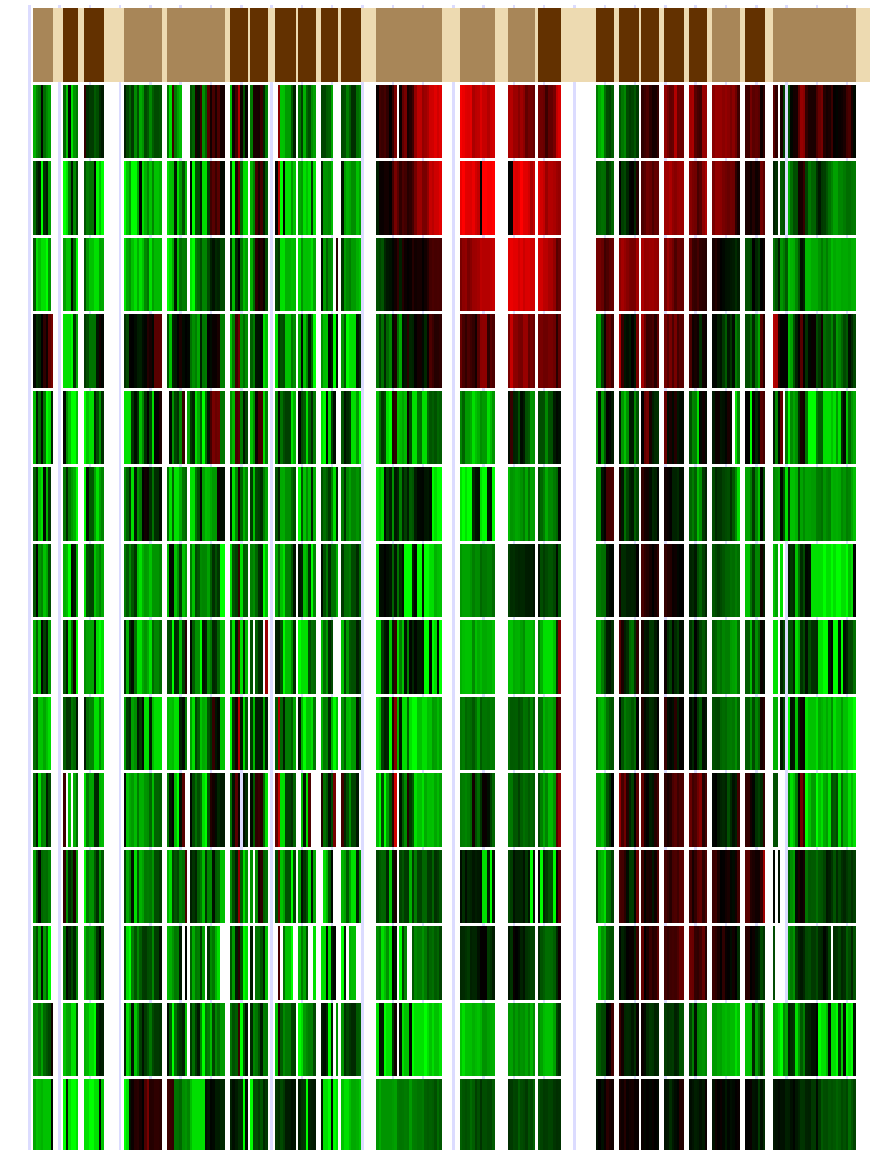

융 $\frac{8}{\frac{1}{5}}$

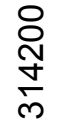
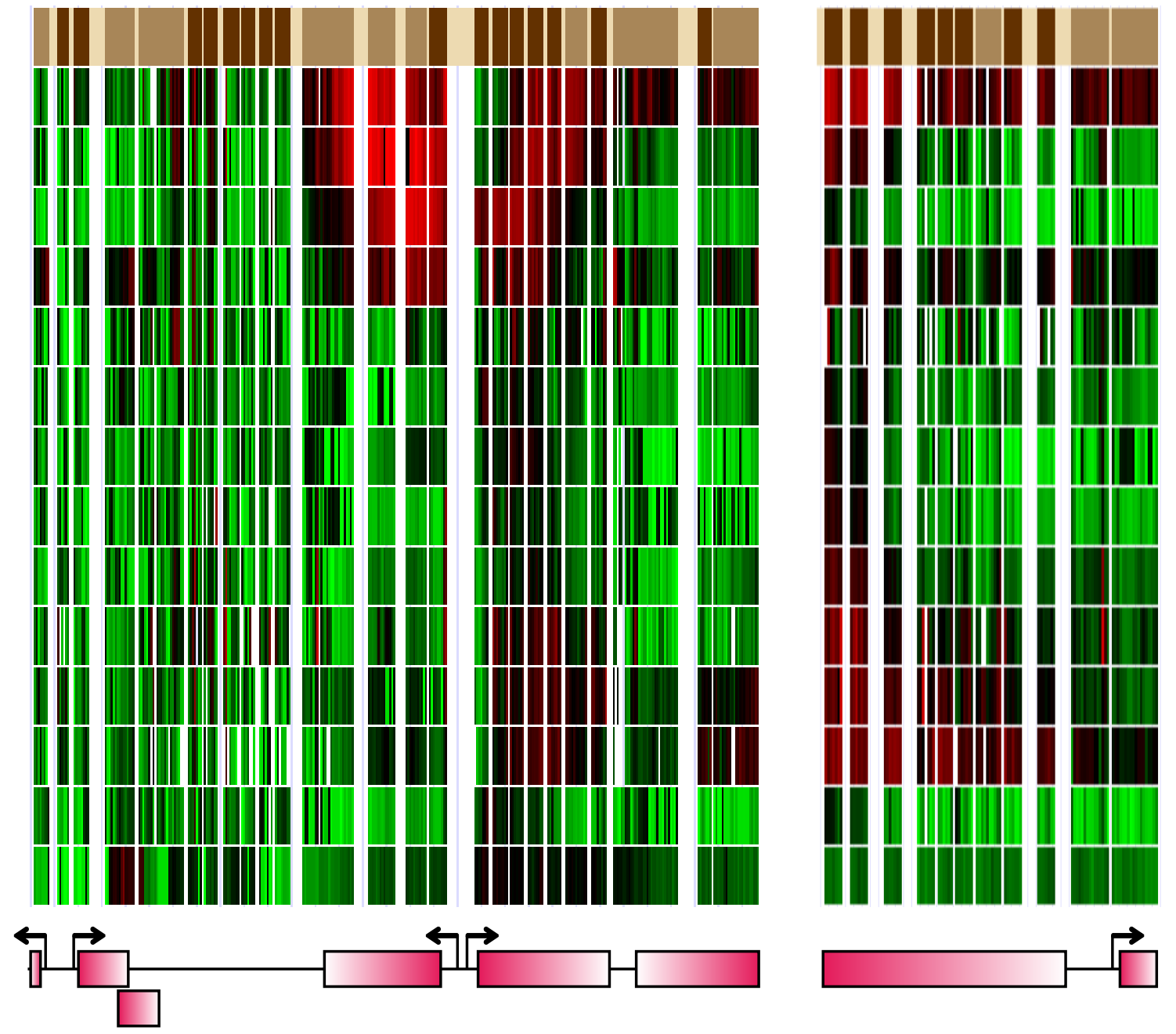

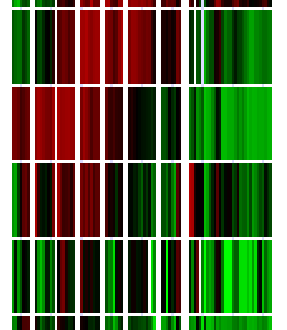

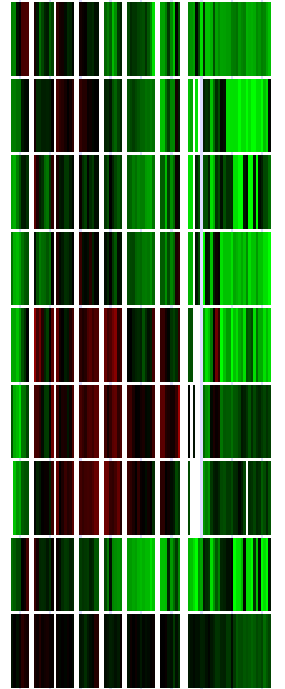

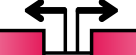

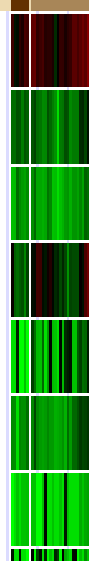
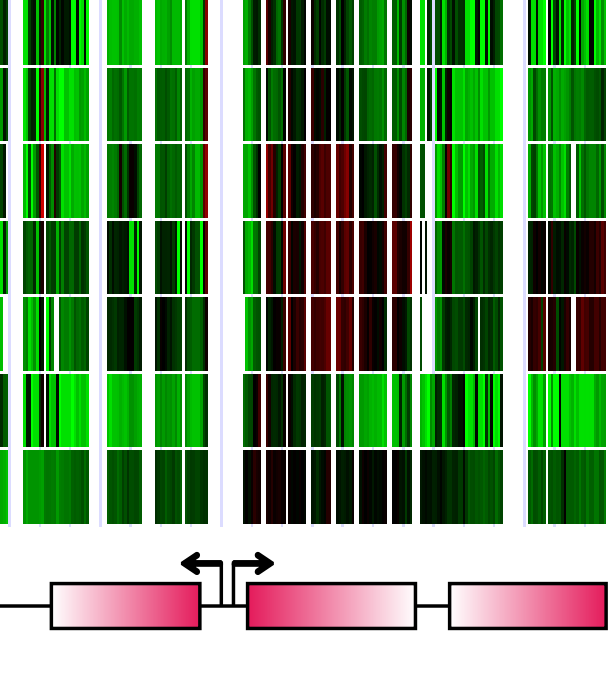